\title{
Nursing Education: Assessment of Healthcare Career Perspectives of First Year Nursing Students
}

\author{
Padmavali Palange, Ritu Vaish, Venkatramana Kandi* \\ Department of Microbiology, Prathima Institute of Medical Sciences, Nagunur, Karimnagar, Telangana, India \\ *Corresponding author: ramana_20021@rediffmail.com
}

\begin{abstract}
Background: Several factors influence the pre-university students to choose healthcare profession as their career. This in turn will have effect on their theoretical, clinical knowledge, and academic performance. It also influences the psycho-motor and problem-solving skills, which are crucial in providing better care to patients. The aim of the study was to assess the healthcare perspectives of first year B.Sc. nursing students and the factors influencing their choice for healthcare profession. Materials and methods: A cross-sectional study was carried out among the B.Sc. nursing first year students at the nursing college associated with Prathima Institute of Medical Sciences (PIMS), affiliated to Kaloji Narayana Rao University of Health Sciences (KNRUHS), in north Telangana during April 2017. A self administered semi structured questionnaire was used for data collection after obtaining an informed verbal consent. 91 students participated in the study. Data was analysed by calculating the percentages and applying the chi square test. Results: Out of 91 students, nursing profession to serve the community was noted to be the first choice 66 (72.5\%). Only 17(18.7\%) students joined nursing profession by their interest. Majority of the students wanted to pursue post-graduation (54 (59.3\%)). 23 (42.6\%) students decided to pursue different clinical subjects whereas $31(57.4 \%)$ students had not yet decided post-graduation subject. 59 (64.8\%) students were interested to go abroad for a job. Majority of the students 52 (57.1\%) opted to work in urban areas whereas 39 (42.9\%) preferred to work in rural setup. 74(81.3\%) students wish to continue nursing profession and 17 (18.7\%) students still had the desire to pursue career in other fields. Conclusion: Serving the community, caring for others, and better earning remains the most common reasons to choose nursing as a profession. Majority of the students wanted to pursue higher education and continue nursing profession in urban areas.
\end{abstract}

Keywords: career, healthcare, nursing students

Cite This Article: Padmavali Palange, Ritu Vaish, and Venkatramana Kandi, "Nursing Education: Assessment of Healthcare Career Perspectives of First Year Nursing Students.” American Journal of Educational Research, vol. 5, no. 6 (2017): 655-659. doi: 10.12691/education-5-6-11.

\section{Introduction}

In society there are several factors which influence preuniversity students to choose a career. Most societies, and especially in India there is a lot of demand for medical and engineering profession, which might be attributed to the fact that they are more respected and earn better than compared to many other professionals. Since nursing is a profession which involves caring for the patients, and working in co-ordination with the treating doctors, it is important to find the reasons as to why one had chosen this as a career. Factors influencing the decision to become a part of healthcare could be previous experience with a loved one or self being ill and/or hospitalized, past health care work experience, and having a family member or friend who was a nurse. Care and concern for others, job security, increased opportunities and variety of work settings remains the main reasons behind choosing healthcare profession as a career [1-11]. These factors can have an influence on their academic performance, theoretical and clinical knowledge, psycho-motor and problem-solving skills which are necessary for providing better patients [12]. Considering the changing health care environment, it is recommended that health care professionals be proficient in specific areas/specialities [13]. Increased number of health care facilities, created improved opportunities among nursing profession. India has been developing to a great extent in this regard, where females have now been able to peruse their choice of career on par with males. Significantly, nursing is such a profession which suits women, especially attributed to their nature which involves selfless work, patience, and mental strength. Social concerns are still prevalent in many regions of the world, including India, regarding females choosing this profession [14]. With this background, we carried out the study to assess the healthcare perspectives of first year Bachelor of Science (B.Sc.) nursing students and factors influencing their choice for healthcare profession.

\section{Materials and Methods}

A cross-sectional, and descriptive study was done among the B.Sc. Nursing first year students at the nursing college associated with Prathima Institute of Medical 
Sciences (PIMS), affiliated to Kaloji Narayana Rao University of Health Sciences (KNRUHS), in north Telangana during April 2017. A self administered semi structured questionnaire was used for data collection after obtaining an informed verbal consent. Total 91 students participated in the study. The demographic details of the subjects collected included age, sex, and residential background.

Initially we have conducted an elaborate literature search to decide the study subjects, and frame the questions to be included in the research. A decision to select first year nursing students was taken, considering the fact that they have just been in to the course and could yield the real perception rather than influences. All the students were divided in to groups of 10-12 students. Each group had a tutor, who explained in detail the purpose of this study and the importance of their opinion in the results of the study. The participants among the groups were allowed to interact, and clear all their doubts, if any with the tutor in charge of the group before filling in the questionnaire. Data was then analysed by calculating the percentages and applying the chi square test.

\section{Results}

A total of 91 students participated in the study. All the participants in the study group were females between the age of 19 and 20 years. Majority of the students i.e. 56 (61.5\%) belonged to urban background and 57 (62.6\%) had done schooling from government schools as shown in Table 1.

Study revealed that nursing profession was the first choice only among 66 (72.5\%) students. Statistically significant difference $(\mathrm{p}=0.03430)$ was noted between career in nursing profession as first choice and area of residence. 45 (80.1\%) rural students and 21 (60\%) urban students preferred career in nursing profession as first choice. Nursing was the first choice among 11 (19.6\%) rural and 14 (40\%) urban students chose a different field as their first choice as shown in Table 2.

The major reason for choosing career in nursing profession was noted to the will to serve or care for the community 53 (58.2\%), followed by better earning opportunities 31 (34.1\%). Other influencing factors included parents wish 25 (27.5\%), and social status 23 (25.3\%). Very few students had an intrinsic interest towards nursing profession $17(18.7 \%)$ as shown in Table 3. A statistically significant difference was observed ( $p=0.01021$ ) regarding better earning between rural and urban area students.

Majority of the students i.e. 54 (59.3\%) wanted to pursue post-graduation. Out of these 23 (42.6\%) students decided to pursue different subjects (had some special interests), whereas 31 (57.4\%) students had not decided on a post-graduation subject yet. The subjects preferred for post-graduation were as follows: Community health nurse 4 (7.4\%), Cardiology 4 (7.4\%), Obstetrics 4 (7.4\%), Gynaecology 3 (5.6\%), Paediatrics 2 (3.7\%), Ophthalmology 2 (3.7\%), Operation theatre Intensive care unit 1 (1.9\%), Infection control nurse 1 (1.9\%), and Orthopaedics 1 (1. 9\%).There was a statistically significant difference $(p=0.01138)$ between rural and urban students willing to pursue post-graduation as shown in Table 4. Out of 91 students, 54 (59.3\%) students were inclined to go further and complete a $\mathrm{PhD}$ (doctor of philosophy). More number of rural students 37 (66.1\%) were interested in doing $\mathrm{PhD}$ compared to urban students 17 (48.6\%).

59 (64.8\%) students had a desire to go abroad in search of better employment. Majority of the students were from rural area 33 (58.9\%) compared to urban area 26 (74.3\%). Government sector was the most preferred sector for work by $72(79.1 \%)$ students, followed by private sector 19 (20.9\%) as shown in Table 4.

Table 1. Characteristics of participants $(n=91)$

\begin{tabular}{|c|c|c|}
\hline \multicolumn{2}{|c|}{ Characteristics of participants } & Number (Percentage) (n=91) \\
\hline \multirow{2}{*}{ Residence: } & Rural & $56(61.5 \%)$ \\
& Urban & $35(38.5 \%)$ \\
\hline \multirow{2}{*}{ Schooling: } & Government & $57(62.6 \%)$ \\
& Private & $34(37.4 \%)$ \\
\hline
\end{tabular}

Table 2. Career in nursing profession - a first choice?

\begin{tabular}{|c|c|c|c|}
\hline \multirow{2}{*}{ Nursing - First choice } & \multicolumn{2}{|c|}{ Area of residence } \\
\cline { 2 - 4 } & Rural (n= 56) & Urban (n=35) \\
\hline Yes & $45(80.1 \%)$ & $21(60 \%)$ & $66(72.5 \%)$ \\
\hline No & $11(19.6 \%)$ & $14(40 \%)$ & $25(27.5 \%)$ \\
\hline
\end{tabular}

$x^{2}=4.48, p$ value $=0.03430$ (significant)

Table 3. Reasons for choosing career in nursing profession

\begin{tabular}{|l|c|c|c|}
\hline \multirow{2}{*}{ Reasons } & \multicolumn{2}{|c|}{ Area of residence } & \multirow{2}{*}{ Total (n=91) } \\
\cline { 2 - 4 } & Rural (n=56) & Urban (n=35) & $53(58.2 \%)$ \\
\hline Serve the community & $35(62.5 \%)$ & $18(51.4 \%)$ & 0.2991 \\
\hline Better earning (foreign) & $14(25 \%)$ & $17(48.6 \%)$ & $31(34.1 \%)$ \\
\hline Parents wish & $12(21.4 \%)$ & $13(37.1 \%)$ & $25(27.5 \%)$ \\
\hline Social status & $16(28.6 \%)$ & $07(20 \%)$ & $23(25.3 \%)$ \\
\hline Interest in nursing profession & $14(25 \%)$ & $0.1023(8.6 \%)$ & $17(18.7 \%)$ \\
\hline
\end{tabular}


Table 4. Career perspectives of nursing students

\begin{tabular}{|c|c|c|c|c|c|}
\hline \multirow{2}{*}{\multicolumn{2}{|c|}{ Career perspectives }} & \multicolumn{2}{|c|}{ Area of residence } & \multirow{2}{*}{ Total $(n=91)$} & \multirow{2}{*}{$p$ value } \\
\hline & & Rural (n=56) & Urban $(n=35)$ & & \\
\hline \multirow{2}{*}{ Pursue post-graduation: } & Yes & 39 (69.6\%) & $15(42.9 \%)$ & 54 (59.3\%) & \multirow{2}{*}{ 0.0113* } \\
\hline & No & 17 (30.4\%) & 20 (57.1\%) & 37 (40.6\%) & \\
\hline \multirow{2}{*}{ PhD: } & Yes & 37 (66.1\%) & 17 (48.6\%) & 54 (59.3\%) & \multirow{2}{*}{0.09826} \\
\hline & No & $19(33.9 \%)$ & $18(51.4 \%)$ & $37(40.6 \%)$ & \\
\hline \multirow{2}{*}{ Plans to go abroad: } & Yes & 33 (58.9\%) & 26 (74.3\%) & 59 (64.8\%) & \multirow{2}{*}{0.1356} \\
\hline & No & $23(41.1 \%)$ & $09(25.7 \%)$ & $32(35.2 \%)$ & \\
\hline \multirow{2}{*}{ Preferred work sector: } & Government & 45 (80.4\%) & 27 (77.1\%) & 72 (79.1\%) & \multirow{2}{*}{0.7136} \\
\hline & Private & $11(19.6 \%)$ & 08 (22.9\%) & 19 (20.9\%) & \\
\hline
\end{tabular}

*significant.

Table 5. Area of residence and preferred location for work

\begin{tabular}{|c|c|c|c|}
\hline \multirow{2}{*}{ Preferred location for work } & \multicolumn{2}{|c|}{ Area of residence } & \multirow{2}{*}{ Total $(\mathrm{n}=91)$} \\
\hline & Rural (n=56) & Urban(n= 35) & \\
\hline Rural & $30(53.6 \%)$ & $9(25.7 \%)$ & 39 (42.9\%) \\
\hline Urban & $26(46.4 \%)$ & $26(74.3 \%)$ & 52 (57.1\%) \\
\hline
\end{tabular}

$\mathrm{x}^{2}=6.825, \mathrm{p}$ value $=0.0089$ (significant)

Table 6. Possibility to change the field from nursing to others

\begin{tabular}{|c|c|c|c|}
\hline \multirow{2}{*}{ Possibility to change the nursing field } & \multicolumn{2}{|c|}{ Area of residence } & \multirow{2}{*}{ Total (n=91) } \\
\cline { 2 - 4 } & Rural (n=56) & Urban (n=35) & $17(18.7 \%)$ \\
\hline Yes & $11(19.9 \%)$ & $06(17.1 \%)$ & $74(81.3 \%)$ \\
\hline No & $45(80.4 \%)$ & $29(82.9 \%)$ & 0.7659 \\
\hline
\end{tabular}

Most students 52 (57.1\%) preferred to work in urban set-up whereas 39 (42.9\%) preferred to work in the rural area. Significant difference was noted with regard to area of residence and preferred location for work. Students belonging to rural background preferred to work in rural areas 30 (53.6\%), whereas students from urban background preferred to work in urban area 26 (74.3\%). A statistically significant difference $(\mathrm{p}=0.0089)$ was observed between rural and urban area students and preferred location for work as shown in Table 5.

The study results reveal that 74 (81.3\%) students wish to continue nursing profession, whereas 17 (18.7\%) students still wanted to pursue career in other field even after completing nursing education. Out of these 17 students, 8 (47.1\%) were interested in becoming doctor, 7 (41.2\%) wanted to study B.Sc. agriculture, 2 (11.8\%) preferred being a school teacher as shown in Table 6 .

\section{Discussion}

Nursing as a profession gained significance in India, way back in 1867, during the British rule due to the efforts of Florence Nightingale, who started training women at the St Stephen's hospital, Delhi. Later, the first government school of nursing was established attached to the government general hospital, Madras [15]. The Indian scenario, where a female's job is thought to be looking after home and the family, being successful in a profession is quite difficult. Historically, women were rarely allowed to peruse a profession. Women, although used to assist deliveries, most physician assistants/compounders were young men. There also is a social sigma, where nursing women suffered discrimination and the profession was considered as not dignified [1]. Nurses might require doing almost end-less work, even sacrificing the holidays.
It can be physically and mentally tiring. Therefore, right attitude is almost a prerequisite in this field, as nursing is considered as the most trusted job.

In our study, all participants were females. Most of the previous studies also reported same sample characteristics $[1,13,16,17,18]$. In our study, 66 (72.5\%) students first choice was nursing profession. The major reason to choose nursing profession was to serve the community 53 (58.2\%), followed by better earning 31 (34.1\%), parents wish 25 (27.5\%), social status 23 (25.3\%), and intrinsic interest in perusing nursing profession $17(18.7 \%)$. Other studies also found that the main characteristic which influenced career decision remains care and concern for others, desire to help, followed by job security, information and advice from practicing nurses, role of family members, friends, parents, mentors, role models, and influence of ideals in career formulation [1-11,13,18].

Majority of the students wanted to pursue post-graduation 54 (59.3\%) in clinical subjects. Our findings are consistent with previous research studies $[6,8,11,12]$, and the results were contradicting to findings from a previous study from India [13].

We observed that 59 (64.8\%) students were interested to go abroad for job considering more salary, better living conditions and increased opportunities. Similar findings were reported by other studies $[13,19]$. This finding is in contrast with another previous study by David M Silvestri et al. [20].

Majority of the students preferred to work in government sector72 (79.1\%) over private sector 21 (23.1\%), believing there will be job security as well as they can serve the poor people. Similar results were noted in a previous report [21].

In our study, we found that majority of students 52 (57.1\%) preferred to work in urban area whereas 39 (42.9\%) were interested to work in rural area as observed 
by previous research reports [20,22]. Students 30 (53.6\%) belonging to rural background preferred to work in rural areas, to serve poor people, followed by more respect, low cost of living, and belong to same area. Whereas students 26 (74.3\%) from urban background preferred to work in urban area because of better opportunities, followed by career growth, better living condition, and more earning. Rural upbringing was not associated with rural job acceptance but higher salary had large effect on nursing students to accept/reject a rural job as noted by previous studies [21,22]. Nursing students showed positive attitude towards working in rural area as observed in a previous report [21].

81.3\% students wished to continue nursing profession because of easy availability of job and respect in society whereas 17 (18.7\%) students still had the desire to pursue career in other fields (open to change) even after completing nursing education.The major reason for interest in other field was more stress, low prestige, disrespect for nursing profession, less freedom during training period, many subjects in nursing curriculum, less time for study, more writing assignments, busy job, less effective teaching, and less relaxation.Our findings are consistent with other research studies in the past $[1,13,23]$. Contradicting results were also noted in a previous report [24]. As noted by the results of the current study and a previous report many nursing students had not planned further than the post-graduation, and had not yet decided the specialization [25].

\section{Conclusion and Recommendations}

Serving the community, care for others, and better earning were the main reasons which influenced the students in their career choice decisions. Majority of the students wanted to pursue higher education, would prefer to go abroad for job, and continue nursing profession. Place of residence of the students could influence the future location of workplace (urban/rural). Overall, there appears to be a positive inclination towards nursing profession in most of the first year nursing students.

It is possible to improve nurse's image and enhance their self-esteem by recognizing the dignity in profession. There is a need for counselling of parents and students for better career options as per student's interests even before joining the course. Furthermore, a stress management program could build students resiliency in coping with unfamiliar environments and the burden of further studies and employment before and after completing the course.

\section{References}

[1] Ludmila Marcinowicz, Anna Owlasiuk, Barbara Slusarska, Danuta Zarzycka and Teresa Pawlikowska. Choice and perception of the nursing profession from the perspective of Polish nursing students: a focus group study. BMC Medical Education (2016) 16: 243.

[2] Hui-Ling Lai, Ya-Ping Lin, Hui-Kuan Chang, Chia-Jung Chen, Tai-Chu Peng, Fwu-Mei Chang. Is nursing profession my first choice? A follow up survey in pre-registeration student nurses. Nurse education today. August 2008Volume 28, Issue 6, Pages 768-776.

[3] Pamala D Larsen, Joan S McGill, Stephanie J Palmer. Factors Influencing Career Decisions: Perspectives of Nursing Students in
Three Types of Programs. Journal of Nursing Education. April 2003 - Volume 42 Issue 4: 168-173.

[4] Peter I. Buerhaus, Karen Donelan, , Linda Norman, Robert Dittus, Nursing Students' Perceptions of a Career in Nursing and Impact of a National Campaign Designed to Attract People into the Nursing Profession. Journal of professional nursing March-April, 2005Volume 21, Issue 2, Pages 75-83.

[5] Mary Mooney, Michele Glacken' Frances O’Brien Choosing nursing as a career: A qualitative study. Nurse education today. April 2008Volume 28, Issue 3, Pages 385-392

[6] Terence V. McCann, Eileen Clark, Sai Lu. Bachelor of Nursing students career choices: A three-year longitudinal study. Nursing education today. January 2010Volume 30, Issue 1, Pages 31-36.

[7] Price, S. L. (2009), Becoming a nurse: a meta-study of early professional socialization and career choice in nursing. Journal of Advanced Nursing, 65: 11-19

[8] Kloster, T., Høie, M. and Skår, R. (2007), Nursing students’ career preferences: a Norwegian study. Journal of Advanced Nursing, 59: 155-162.

[9] Teodosio Sheila Saint-Clair, Padilha Maria Itayra. "To be a nurse": a professional choice and the construction of identity processes in the 1970s. Rev. Bras. Enferm. [Internet]. 2016 June [cited 2017 May 16]; 69(3): 428-434.

[10] Paola Ferri, PatriziaLaffi, Sergio Rovesti, Giovanna Artioli, Rosaria Di Lorenzo, Daniela Magnani. Motivational factors for choosing the degree course in nursing: a focus group study with nursing students. Acta Biomed for Health Professions 2016; Vol. 87, S. 2: 19-27.

[11] TawashEman, Cowman Seamus, Anunciacion Edgar. A triangulation study: Bahraini nursing students' perceptions of nursing as a career. Journal of Nursing Education and Practice, August 2012, Vol. 2, No. 3.

[12] Mary T. Hickey. Baccalaureate Nursing Graduates' Perceptions of Their Clinical Instructional Experiences and Preparation for Practice. Journal of professional nursing. January 2010 Volume 26, Issue 1, Pages 35-41.

[13] Anurag B. Patidar, Jasbir Kaur, Suresh K Sharma, Neeraj Sharma. Future nurses' perception towards profession and carrier plans: A cross sectional survey in state Punjab. Nursing and Midwifery Research Journal, Vol-7, No. 4, October 2011.

[14] Poreddy V, Ramachandra Koduru R, Math SB. Assessing the attitudes and perception towards nursing profession among nursing students. Nurs J India. 2002; 103 (1): 6-8.

[15] Wilkinson, Alice (1958). A brief history of nursing in India and Pakistan. Delhi: Trained nurses association of India. p 115.

[16] Lai HL, Peng TC, Chang FM. Factors associated with career decision in Taiwanese nursing students: a questionnaire survey. International Journal of Nursing Studies 2006; Jul; 43(5):581-88.

[17] Lisa M. Pugsley. Poster presentation: Nurses' Attitudes toward Their Profession. Water's Edge Ballroom, Hilton Waikoloa Village. Jul; 2005.

[18] O'Brien F, Mooney M, Glacken M. Impressions of nursing before exposure to the field. J ClinNurs2008; Jul;17(14):1843-50.

[19] Kingma, M. (2001), Nursing migration: global treasure hunt or disaster-in-the-making?. Nursing Inquiry, 8: 205-212.

[20] David M Silvestri, Meridith Blevins, Arfan R Afzal, Ben Andrews, MiliardDerbew, Simran Kaur, MwapatsaMipando, Charles A Mkony, Philip M Mwachaka, NirjuRanjiti\&StenVermunda. Medical and nursing students' intentions to work abroad or in rural areas: a cross-sectional survey in Asia and Africa. Bulletin of the World Health Organization. September 2014.

[21] Krisada Sawaengdee, Nareerut Pudpong, Thunthita Wisaijohn, Rapeepong Suphanchaimat, Weerasak Putthasri, Mylene Lagarde and Duane Blaauw. Factors associated with the choice of public health service among nursing students in Thailand. BMC Nursing (2017) 16: 8.

[22] Rao KD, Ryan M, Shroff Z, Vujicic M, Ramani S, et al. (2013) Rural Clinician Scarcity and Job Preferences of Doctors and Nurses in India: A Discrete Choice Experiment. PLoS ONE 8(12): e82984.

[23] Insaf A. Shaban, Wejdan A. Khater, Laila M. Akhu-Zaheya. Undergraduate nursing students' stress sources and coping behaviours during their initial period of clinical training: A Jordanian perspective. Nurse education in practice. July 2012. Volume 12, Issue 4, Pages 204-209. 
[24] Pelletier D, Donoghue J, Duffield C. Understanding the nursing workforce: a longitudinal study of Australian nurses six years after graduate study. Aust J Adv Nurs2005; Sep Nov; 23(1): 37-43.
[25] Happell B. When I grow up I want to be a...? Where undergraduate student nurses want to work after graduation. J Adv Nurs. 1999 Feb; 29(2):499-505. 